\title{
Kriteria Kemasakan Buah Pepaya (Carica papaya L.) IPB Callina dari Beberapa Umur Panen
}

\author{
Criteria of Postharvest Ripeness of IPB Callina Papaya Fruit (Carica papaya L.) \\ of Several Harvesting Age
}

M. Luthfan Taris ${ }^{1}$, Winarso D. Widodo ${ }^{1 *}$, dan Ketty Suketi ${ }^{1}$

Diterima 19 Agustus 2015/Disetujui 09 November 2015

\begin{abstract}
Papaya is one of the climacteric fruit that has a short shelf life. It has high potential as a source of vitamins and minerals. This research was aimed at studying the maturity criteria of postharvest ripeness of Callina papaya fruit of several picking ages and to determine the best picking ages for postharvest handling in order to extend the shelf life. Experiment was conducted in the Research Center for Tropical Horticulture, Bogor Agricultural University (PKHT, IPB) Papaya Farm Tajur, Bogor and postharvest ripening test was conducted at Postharvest Laboratory, Department of Agronomy and Horticulture, Bogor Agricultural University in February to July 2014. Experiment consisted of 4 treatments: 115, 120, 125 and 130 days after anthesis (DAA) with 3 replications. The longest shelf life for papaya Callina was obtained by fruit picked at 115 DAA (heat unit $2010.06{ }^{\circ} \mathrm{C}$ day) with the shelf life of 8 days. Picking ages 120 DAA (heat unit $2102.13{ }^{\circ} \mathrm{C}$ day) was the best picking ages for treatment to extend the shelf life because of the good chemical quality contained and its shelf life of 7 days. The older papay a fruits ripened faster than the younger papaya fruit. Younger papaya has a lower respiration rate than the older papaya. Picking ages did not affect the physical quality but affect the chemical quality of papaya fruit at the same postharvest maturity level.
\end{abstract}

Kata kunci: Callina, chemical quality, physical quality, shelf life

\begin{abstract}
ABSTRAK
Pepaya merupakan salah satu buah klimakterik yang memiliki daya simpan pendek, tetapi memiliki potensi yang tinggi sebagai sumber vitamin dan mineral. Penelitian ini bertujuan untuk mempelajari kriteria kematangan pascapanen buah pepaya Callina dari beberapa umur panen dan menentukan saat panen terbaik untuk penanganan pascapanen dalam rangka memperpanjang masa simpan. Buah untuk percobaan diperoleh dari kebun pepaya Pusat Kajian Hortikultura Tropika, Institut Pertanian Bogor (PKHT, IPB) Tajur, Bogor dan pengujian kematangan pascapanen dilakukan di Laboratorium Pascapanen, Departemen Agronomi dan Hortikultura, Institut Pertanian Bogor pada bulan Februari - Juli 2014. Percobaan terdiri atas 4 perlakuan: 115, 120, 125 dan 130 hari setelah antesis (HSA) dengan 3 ulangan. Umur simpan terlama pepaya Callina diperoleh pada umur panen 115 HSA (satuan panas sebesar $2010.06{ }^{\circ} \mathrm{C}$ hari) dengan umur simpan 8 hari. Umur panen 120 HSA (satuan panas sebesar $2102.13{ }^{\circ} \mathrm{C}$ hari) merupakan umur panen terbaik untuk perlakuan memperpanjang umur simpan karena mutu kimia baik dengan umur simpan 7 hari. Buah pepaya yang dipanen tua lebih cepat masak dibandingkan dengan buah pepaya yang dipanen muda. Pepaya yang dipanen muda memiliki laju respirasi yang lebih rendah dibandingkan dengan pepaya yang dipanen tua. Umur panen tidak mempengaruhi mutu fisik tetapi mempengaruhi mutu kimia buah pepaya pada tingkat kematangan pascapanen yang sama.
\end{abstract}

Kata kunci: Callina, mutu fisik, mutu kimia, umur simpan

\footnotetext{
${ }^{1}$ Departemen Agronomi dan Hortikultura, Fakultas Pertanian, Institut Pertanian Bogor (Bogor Agricultural University), J1. Meranti Kampus Darmaga, Bogor 16680 Indonesia. Telp.\&Faks. 62-251-8629353. email: wd_widodo@yahoo.com. (*penulis korespondensi)
} 


\section{PENDAHULUAN}

Pepaya tergolong dalam buah dengan respirasi klimakterik. Buah dengan respirasi klimakterik adalah buah dengan produksi $\mathrm{CO}_{2}$ yang tinggi selama proses pemasakan (ripening) buah dan produksi etilen yang tinggi. Produksi etilen yang tinggi menyebabkan masak buah yang lebih cepat. Kecepatan masak buah ini dapat mempengaruhi umur simpan buah. Umur simpan buah pepaya juga dapat dipengaruhi oleh faktor prapanen dan pascapanen.

Faktor prapanen sangat mempengaruhi kualitas buah pada saat panen. Kualitas produk pascapanen dipengaruhi perkembangan produk selama awal pertumbuhan tanaman, saat pertumbuhan dan teknologi pascapanen (Hewett, 2006). Komposisi gizi buah saat panen dapat bervariasi bergantung pada kultivar, kematangan buah, iklim, jenis tanah, dan kesuburan (Lee dan Kader, 2000). Faktor iklim khususnya suhu dan intensitas cahaya memiliki dampak yang besar pada kualitas buah (Knee, 2002). Suhu merupakan faktor lingkungan penting yang menentukan kualitas dan tingkat kerusakan pada buah pepaya. Suhu mempengaruhi metabolisme dan penyerapan nutrisi mineral oleh tanaman karena tingkat transpirasi meningkat seiring dengan meningkatnya suhu. Suhu kurang dari $10{ }^{0} \mathrm{C}$ menurunkan pertumbuhan buah, tingkat kemanisan dan ukuran buah pepaya. (Workneh et al., 2012).

Waktu panen yang tepat dapat mempengaruhi kualitas pepaya yang akan dipasarkan. Buah pepaya dipanen pada stadia menguning yaitu saat muncul garis-garis kuning pada permukaan kulit buah. Pada stadia ini menunjukkan pepaya mencapai matang fisiologis (mature) dan akan masak (ripened) (Directorate Agricultural Information Services Department of Agriculture, Forestry and Fisheries, 2009). Pepaya yang dipanen pada stadia matang pohon ini belum diketahui lama masa simpannya hingga mencapai kemasakan. Penelitian ini dilaksanakan untuk mempelajari pengaruh umur panen terhadap kriteria kemasakan buah pepaya IPB Callina saat mencapai tingkat kemasakan optimum dan menentukan saat panen terbaik untuk penanganan pascapanen yang dapat memperpanjang masa simpan.

\section{BAHAN DAN METODE}

Percobaan ini dilaksanakan di kebun pepaya Pusat Kajian Hortikultura Tropika, Institut pertanian Bogor (PKHT, IPB) Tajur, Bogor dan Laboratorium Pascapanen, Departemen Agronomi dan Hortikultura, Institut Pertanian Bogor pada bulan Februari hingga Juli 2014.

Rancangan percobaan yang digunakan adalah rancangan kelompok lengkap teracak (RKLT) yang dikelompokkan berdasarkan umur panen. Percobaan ini dilaksanakan dengan percobaan faktor tunggal yaitu umur panen buah papaya Callina yang terdiri atas 4 taraf yaitu 115, 120, 125 dan 130 hari setelah antesis (HSA) dengan 3 ulangan. Jumlah satuan percobaan adalah 12 satuan percobaan. Setiap satuan percobaan terdiri dari 3 buah pepaya. Jumlah buah pepaya keseluruhan yang digunakan sebanyak 36 buah. Untuk mendapatkan umur panen, dilakukan penandaan saat bunga antesis. Bunga yang ditandai adalah bunga dari tanaman hermafrodit. Pengamatan yang dilakukan meliputi suhu harian rata-rata dari anthesis hingga panen, sesuai dengan perlakuan umur panen, laju respirasi selama penyimpanan, umur simpan yang diamati mulai dari 0 hari setelah panen hingga warna kulit buah mencapai skala warna 6 atau 7 , kriteria kemasakan fisik (indeks skala warna kulit buah, susut bobot buah, kekerasan daging dan kulit buah), padatan terlarut total (PTT), asam tertitrasi total (ATT), dan kandungan vitamin $\mathrm{C}$ pada saat buah mencapai masak optimum (skala warna kulit 6 atau 7). Pengamatan mutu fisik dan kimia buah mengacu metode yang digunakan Prasetyo (2013). Pengamatan skala warna kulit buah mengacu metode yang digunakan oleh Rini (2008) sebagai berikut: hijau, hijau dengan sedikit kuning, hijau kekuningan, kuning lebih banyak dari hijau, kuning dengan ujung hijau, kuning penuh, kuning dengan sedikit bintik coklat.

\section{HASIL DAN PEMBAHASAN}

\section{Umur Simpan}

Umur simpan merupakan parameter utama untuk mengetahui daya simpan dan mutu buah pepaya yang sampai ke tangan 
konsumen. Hasil penelitian menunjukkan bahwa semakin tua umur petik, semakin cepat masak sehingga masa simpan buah semakin pendek. Faktor prapanen khususnya suhu mempengaruhi kondisi pepaya saat dipanen. Suhu mem-pengaruhi metabolisme dan penyerapan nutrisi mineral oleh tanaman karena tingkat transpirasi meningkat dengan meningkatnya suhu. Pengukuran suhu harian di lapangan dilakukan untuk menentukan satuan panas selama proses perkembangan buah. Satuan panas dan umur simpan pepaya IPB Callina saat mencapai skala 6 atau 7 (Tabel 1).

Tabel 1. Satuan panas dan umur simpan pepaya IPB Callina dari beberapa umur panen

\begin{tabular}{ccc}
\hline $\begin{array}{c}\text { Umur Panen } \\
(\text { HSA })\end{array}$ & $\begin{array}{c}\text { Satuan Panas } \\
\left({ }^{0} \mathrm{C} \text { hari) }\right.\end{array}$ & $\begin{array}{c}\text { Umur Simpan } \\
\text { (HSP) }\end{array}$ \\
\hline 115 & 2010.06 & $7.9 \mathrm{a}$ \\
120 & 2102.13 & $6.5 \mathrm{ab}$ \\
125 & 2167.63 & $5.3 \mathrm{bc}$ \\
130 & 2241.75 & $4.1 \mathrm{c}$ \\
\hline Keterangan: Angka yang diikuti huruf berbeda pada \\
\\
\multicolumn{3}{c}{ kolom yang sama berbeda nyata menurut } \\
& uji duncan's multiple range test (DMRT) \\
& pada taraf $\alpha=5 \%$.
\end{tabular}

Pada Tabel 1 diketahui bahwa, pepaya IPB Callina yang dipanen pada umur 115 HAS telah mencapai satuan panas $2010{ }^{\circ} \mathrm{C}$ hari. Selama proses pertumbuhan buah didapatkan suhu minimum harian lapang sebesar $16{ }^{\circ} \mathrm{C}$, sehingga suhu lingkungan optimum untuk pertumbuhan pepaya. Suhu kurang dari $10{ }^{\circ} \mathrm{C}$ menurunkan pertumbuhan buah, tingkat kemanisan dan ukuran buah pepaya (Workneh et al., 2012). Umur simpan yang paling lama didapat pada umur panen 115 HSA yaitu yang berkisar antara 7 sampai 9 HSP.

\section{Laju Respirasi}

Pada buah klimaterik, disamping terjadi kenaikan laju respirasi juga terjadi kenaikan kadar etilen selama proses pemasakan. Laju respirasi buah pepaya IPB Callina pada beberapa umur petik dapat dilihat pada Gambar 2. Laju respirasi dipengaruhi beberapa faktor seperti suhu, umur petik dan kondisi fisik buah. Dari data yang diperoleh dapat dilihat bahwa buah yang dipanen pada umur yang lebih tua menunjukkan laju respirasi yang lebih tinggi dibandingkan dengan buah yang dipanen muda. Laju respirasi yang paling cepat meningkat terjadi pada buah pepaya yang dipanen pada umur 130 HSA. Pada Gambar 1 terlihat bahwa laju respirasi meningkat hingga satu hari sebelum pepaya masak optimum dengan warna kulit mencapai skala 6 atau 7. Respirasi menurun atau stabil saat sehari sebelum pepaya matang. Respirasi stabil di satu hari sebelum pepaya matang disebabkan oleh pepaya yang mengalami memar karena benturan yang terjadi saat transportasi ke laboratorium.

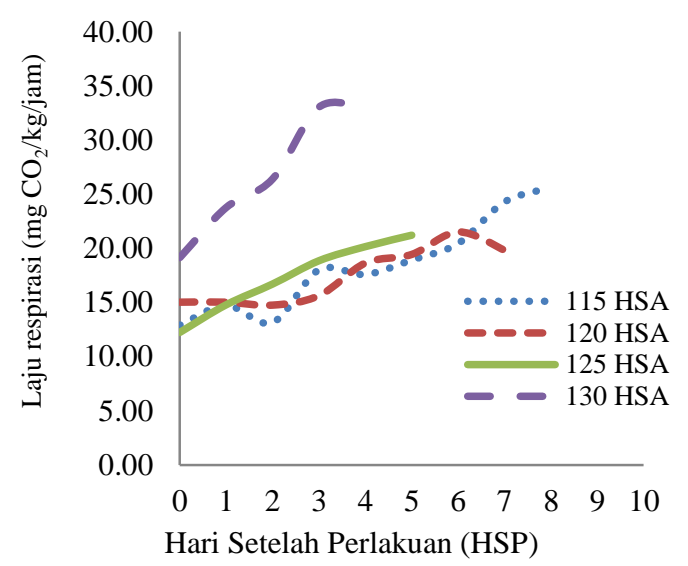

Gambar 2. Laju respirasi buah pepaya setelah pemanenan

Memar akibat benturan dapat menyebabkan perubahan pola respirasi pada buah. Paramita (2010) menyatakan bahwa memar berpengaruh terhadap perubahan pola respirasi dan produksi etilen buah mangga (Mangifera indica L.) varietas Gedong Gincu selama penyimpanan. Buah mangga yang mengalami memar akan mengakibatkan pola respirasi dan produksi etilen meningkat.

\section{Mutu Fisik}

Kondisi fisik dapat dijadikan kriteria bahwa kondisi buah masih layak dikonsumsi. Buah yang akan dipasarkan jauh dari sentra produksi dapat diberi perlakuan untuk mempertahankan kondisi fisik buah, seperti pemberian oksidan etilen. Hasil pengukuran mutu fisik yaitu susut bobot, kelunakan kulit dan daging buah pada skala warna 6 atau 7 disajikan pada Tabel 2. Pada proses pemasakan buah terjadi penurunan bobot buah pepaya, namun dalam percobaan ini umur panen tidak mempengaruhi susut bobot selama 
penyimpanan. Umur panen juga tidak mempengaruhi kelunakan kulit dan kelunakan daging buah pada saat mencapai masak optimum.

\section{Mutu Kimia}

Mutu buah berkaitan dengan perubahan komposisi kimia buah yang akan mempengaruhi rasa buah. Kualitas kimia menjadi penting diamati karena merupakan salah satu faktor yang menentukan kualitas dari keseluruhan buah. Kualitas kimia buah berpengaruh terhadap kandungan gizi yang dapat mempengaruhi penerimaan konsumen terhadap buah yang akan dikonsumsi. Hasil pengukuran padatan terlarut total, asam tertitrasi total dan kandungan vitamin $\mathrm{C}$ pada skala warna 6 atau 7 disajikan pada Tabel 3 .

Umur petik mempengaruhi komposisi kimia buah. Kandungan padatan terlarut total dan kandungan vitamin $\mathrm{C}$ semakin tinggi dengan bertambahnya umur panen. Peningkatan padatan terlarut total ini disebabkan pada tahap awal perkembangan buah, glukosa adalah gula dominan.

Tabel 2. Kualitas fisik pepaya Callina pada skala warna 6 atau 7

\begin{tabular}{cccc}
\hline $\begin{array}{c}\text { Umur } \\
\text { Panen } \\
(\text { HSA })\end{array}$ & $\begin{array}{c}\text { Susut } \\
\text { Bobot } \\
(\%)\end{array}$ & $\begin{array}{c}\text { Kelunakan } \\
\text { Kulit Buah } \\
\left(\mathrm{mm} \mathrm{g}^{-1}\right. \\
\left.\text { detik }^{-1}\right)\end{array}$ & $\begin{array}{c}\text { Kelunakan } \\
\text { Daging Buah } \\
\left(\mathrm{mm} \mathrm{g}^{-1}\right. \\
\left.\text { detik }^{-1}\right)\end{array}$ \\
\hline 115 & 4.72 & 0.12 & 0.36 \\
120 & 4.30 & 0.12 & 0.36 \\
125 & 3.92 & 0.13 & 0.37 \\
130 & 3.03 & 0.12 & 0.38 \\
\hline
\end{tabular}

Tabel 3. Kualitas kimia pepaya Callina pada skala warna 6 atau 7

\begin{tabular}{|c|c|c|c|}
\hline $\begin{array}{l}\text { Umur } \\
\text { Panen } \\
\text { (HSA) }\end{array}$ & $\begin{array}{l}\text { Padatan } \\
\text { Terlarut } \\
\text { Total } \\
\left({ }^{\circ} \text { Brix }\right)\end{array}$ & $\begin{array}{c}\text { Asam } \\
\text { Tertitrasi } \\
\text { Total } \\
\text { (mg } 100 \mathrm{~g}^{-1} \\
\text { edible } \\
\text { portion) }\end{array}$ & $\begin{array}{c}\text { Kandungan } \\
\text { Vitamin C } \\
\text { (mg } 100 \mathrm{~g}^{-1} \\
\text { edible } \\
\text { potion) }\end{array}$ \\
\hline 115 & $9.26 \mathrm{c}$ & 8.27 & $40.68 b$ \\
\hline 120 & $10.88 b$ & 8.71 & $42.87 b$ \\
\hline 125 & $10.99 b$ & 9.07 & $47.25 \mathrm{ab}$ \\
\hline 130 & $12.62 \mathrm{a}$ & 9.96 & $55.07 \mathrm{a}$ \\
\hline Keterangan: & \multicolumn{3}{|c|}{$\begin{array}{l}\text { Angka yang diikuti huruf berbeda pada } \\
\text { kolom yang sama berbeda nyata menurut } \\
\text { uji duncan's multiple range test (DMRT) } \\
\text { pada taraf } \alpha=5 \% \text {. }\end{array}$} \\
\hline
\end{tabular}

Sementara pada tahap pramasak dan masak kenaikan sukrosa dalam buah 2 hingga 5 kali lipat lebih tinggi dibandingkan fruktosa dan glukosa (Workneh et al., 2012). Menurut Istianingsih dan Efendi (2013), terdapat interaksi yang signifikan antara umur panen buah naga Super Red dan suhu ruang penyimpanan, terhadap mutu fisik buah, seperti kehilangan hasil kumulatif dan kekerasan buah. Kandungan vitamin $\mathrm{C}$ dalam pepaya pada semua umur panen berkisar

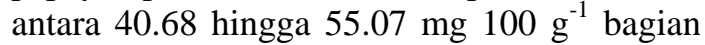
dapat dimakan.

Hasil penelitian lain kandungan vitamin $\mathrm{C}$ pada pepaya 68.90 hingga $96.90 \mathrm{mg} 100 \mathrm{~g}^{-1}$ bagian dapat dimakan (Adriana, 1996), 51.24

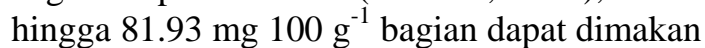
(Prasetyo, 2013), dan 46.30-125.90 mg $100 \mathrm{~g}^{-1}$ bagian dapat dimakan (Pal et al., 1980). Kandungan asam tertitrasi total buah pepaya pada 4 umur panen yang diuji tidak menunjukkan perbedaan nyata (Tabel 3). Bron dan Jacomino (2006) melaporkan bahwa asam askorbat (AA) dalam pepaya meningkat 20 sampai $30 \%$ selama proses pemasakan dan tidak tergantung tingkat kematangan pepaya saat panen. Workneh et al. (2012) menyatakan bahwa selama proses pemasakan buah pepaya terjadi peningkatan keasaman total, yang diyakini terkait dengan peningkatan asam galakturonat bebas.

\section{KESIMPULAN}

Mutu fisik buah pepaya Callina pada tingkat kemasakan pascapanen yang sama tidak dipengaruhi oleh umur panen (115 - 130 HSA). Semakin tua umur panen kandungan PTT dan vitamin $\mathrm{C}$ semakin tinggi. Umur simpan terlama pepaya IPB Callina diperoleh pada buah yang dipanen 115 HSA (satuan panas sebesar $2010.06{ }^{\circ} \mathrm{C}$ hari) dengan umur simpan 8 HSP. Umur simpan buah pepaya yang dipanen pada 115 HSA tidak berbeda dengan umur simpan buah yang dipanen pada 120 HSA (satuan panas sebesar $2102.13{ }^{\circ} \mathrm{C}$ hari). Pepaya Callina mulai dapat dipanen saat jumlah satuan panas sekitar $2100{ }^{\circ} \mathrm{C}$ hari. Umur panen 120 HSA merupakan umur panen terbaik untuk perlakuan memperpanjang umur simpan. 


\section{DAFTAR PUSTAKA}

Adriana, D. 1996. Pengaruh pemberian putresin pada berbagai konsentrasi terhadap perubahan kualitas buah pepaya (Carica papaya L.) varietas Dampit. Skripsi. Institut Pertanian Bogor. Bogor.

Bron, H.V., A.P. Jacomino. 2006. Ripening and quality of Golden papaya fruit harvested at different maturity stages. Braz. J. Plant Physiol. 18: 389-396.

Directorate of Agricultural Information Services Department of Agriculture, Forestry and Fisheries. 2009. Cultivating Papayas. Department of Agriculture, Forestry and Fisheries. Pretoria. Afrika Selatan.

Istianingsih, T., D. Efendi. 2013. Pengaruh umur panen dan suhu simpan terhadap umur simpan buah naga Super Red (Hylocereus costaricensis) J. Hort. Indonesia. 4(1): 54-61.

Hewett, E.W. 2006. An overview of preharvest factors influencing postharvest quality of horticultural products. Int. J. Postharv. Technol. Innov. 1(1): 4-15.

Knee, M. 2002. Fruit Quality and Its Biological Basis. Sheffield Academic Press. Sheffield. Inggris.
Lee, S.K., A.A. Kader. 2000. Preharvest and postharvest factors influencing vitamin C content of horticultural crops. Postharv. Biol. Technol. 20: 207-220.

Pal, D.K., C.P.A. Iyes, N.G. Divakar, Y Selvaraj, M.D. Subramanyam. 1980. Studies on the physico chemical composition of fruits of twelve papaya varieties. J. Food. Sci. Technol. 17(6): 254-256.

Paramita, O. 2010. Pengaruh memar terhadap perubahan pola respirasi, produksi etilen dan jaringan buah mangga (Mangifera indica L.) var Gedong Gincu pada berbagai suhu penyimpanan. J. Kompetensi Teknik. 2(1): 29-37.

Prasetyo, H.E. 2013. Efektivitas jumlah kemasan oksidan etilen terhadap kualitas dan daya simpan buah pepaya. Skripsi. Institut Pertanian Bogor. Bogor.

Rini, P. 2008. Pengaruh sekat dalam kemasan kardus terhadap masa simpan dan mutu pepaya IPB 9. Skripsi. Institut Pertanian Bogor. Bogor.

Workneh, T.S., M. Azene, S.Z. Tesfay. 2012. A review on the integrated agrotechnology of papaya fruit. Afr. J. Biotechnol. 11(85): 15098-15110. 